\title{
Reflective assignments by students completing an undergraduate psychiatry attachment
}

\author{
Aileen O'Brien, ${ }^{1}$ Jeremy Mudunkotuwe ${ }^{2}$
}

The Psychiatrist (2012), 36, 470-474, doi: 10.1192/pb.bp.111.037531

${ }^{1}$ St George's, University of London;

${ }^{2}$ West Park Hospital, Epsom

Correspondence to Aileen O'Brien (aobrien@sgul.ac.uk)

First received 20 Oct 2011, accepted 27 Jun 2012

\begin{abstract}
Aims and method Students at St George's, University of London, complete a long case with a reflective component as part of their psychiatry attachment. This consists of a case history and reflection about how meeting the patient has affected them and how it will change their practice. This study aimed to analyse the reflection content, to better understand the student psychiatry experience. A hundred consecutive assignments underwent content analysis to establish the main themes.
\end{abstract}

Results Six main themes were elicited: stigma, social and cultural aspects of psychiatry, fear of mental illness in the students themselves, fear of conducting the interview and criticism of the care the patient received.

Clinical implications Negative attitudes towards psychiatry are common among medical students, although many showed mature reflection. Anxiety about interviewing patients with mental illness should be acknowledged by educators.

\section{Declaration of interest None.}

Reflective practice refers to the process of looking at one's own professional behaviour with the aim of developing and improving it. It allows us to question and learn from experience and to recognise the uncertainty that is often part of clinical medicine, as well as to consider the impact that patients' problems may have on us.

The reflective cycle is described by Gibbs; one reports an event, relates how it made one feel, evaluates what was good and bad about the experience, analyses what sense one made of the situation and concludes what else one could have done and what to do next time. ${ }^{1}$ Increasingly, students are asked to introduce reflective practice to the undergraduate experience. Reflection is being used in selection, in foundation programmes and subsequent revalidation.

To our knowledge, no previous research has analysed the content of medical students' reflection to see whether there are common themes expressed after exposure to psychiatric teaching. In general practice a similar task led students to reflect on learning experiences and key features. ${ }^{2}$ Awareness of common themes may aid the way teaching is shaped and help teachers to better understand the challenges and experience of students. It may also increase understanding about students' attitudes towards psychiatry.

Undergraduate training does have a great influence on students' career preference. ${ }^{3}$ There is a recruitment crisis in psychiatry in the $\mathrm{UK}^{4}$ and it is recognised that the stigma experienced by psychiatric patients extends to both the specialty and the practitioners. ${ }^{5,6}$ It may be possible to change those attitudes using reflection. Some practitioners have tried adopting reflective practice to address negative attitudes towards other specialties; for example, Westmoreland et al set out to improve the attitude of students towards the elderly using a reflective writing exercise (as well as meeting a 'council of elders') and reported an improvement as measured by the Geriatrics Attitudes Scale. ${ }^{7}$

The reflective assignments at St George's form part of a formative assessment of students in the penultimate year of a 5- or 4-year MBBS course (non-graduate and graduate streams). The students are asked to obtain a psychiatric history from a patient and submit a written assignment of a summary of the case. This is accompanied by a personal reflective assignment based on up to three key factors in the case they have discussed.

The aims of this study were to evaluate the content of the reflective assignments and assess students' attitudes to completing the task.

\section{Method}

The psychiatry attachment at St George's is a 6-week clinical attachment the students complete during their penultimate year. The attachment consists of general clinical experience with a psychiatric team, specialist visits, clinical problem-based tutorials and lectures. It is assessed at the end by a formative long case and, at the time of the study, an Objective Structured Clinical Examination (OSCE, now replaced by workplace-based assessments). All students complete a long case. This is a summary of the psychiatric history of a patient they have seen during the attachment. The students are asked to include a reflective 
assignment, describing the impact the patient's problem has on both the patient and the student, and to explain how meeting this patient and the reflective process will change their practice. As part of their professional behaviour teaching, all students have been introduced to the concepts of reflective writing and need to write reflectively in other parts of the course.

About 300 students a year complete the long case; there are about 50 in each attachment which runs 6 times over the year. A hundred consecutive assignments were selected for inclusion in the study. All assignments were anonymised. We first completed a formal conceptual analysis of 20 student assignments each, separately. Both of us had previous experience of marking these types of assignments. By a process of selective reduction we identified themes that occurred in the text. Together, we compared the themes and generated six common ones (Table 1). Each of us then reviewed the same 20 assignments with the coded themes as a guide to assess the frequency of themes in each assignment. Each assignment could contain none, one or more themes coded for. We compared results and discussed issues to improve intercoder reliability and any discrepancies in the coding rules. Once this was established, we reviewed a further 40 assignments each. The frequency of each theme recorded was coded for (Fig. 1) and free-text comments were recorded to illustrate the themes. We then combined and analysed our results.
In addition, it was decided to evaluate the students' experience of completing the long case and reflective piece. Two questions were put forward to one group of 40 students at the end of the psychiatry attachment to assess their thoughts on the process of reflection they had undertaken. Students were asked to rate on a scale (ranging from strongly agree to strongly disagree) how they found the task of writing the summary and the piece of reflection.

\section{Results}

Theme frequencies and representative statements for each theme were collated in a central database. After the data collection was completed, the results were analysed using Microsoft Excel.

The common themes and their frequency are shown in Table 1. It should be noted that 19 (19\%) of the assignments analysed did not contain any of the themes identified.

\section{Stigma of mental illness}

Twenty-seven per cent of the assignments contained the theme of stigma of mental illness in the community. The statements below were representative.

'My ideas were based around negative press stories of psychiatric patients who were a risk to society'.

This quote was indicative of the increased awareness of stigma during the course of the psychiatric attachment.

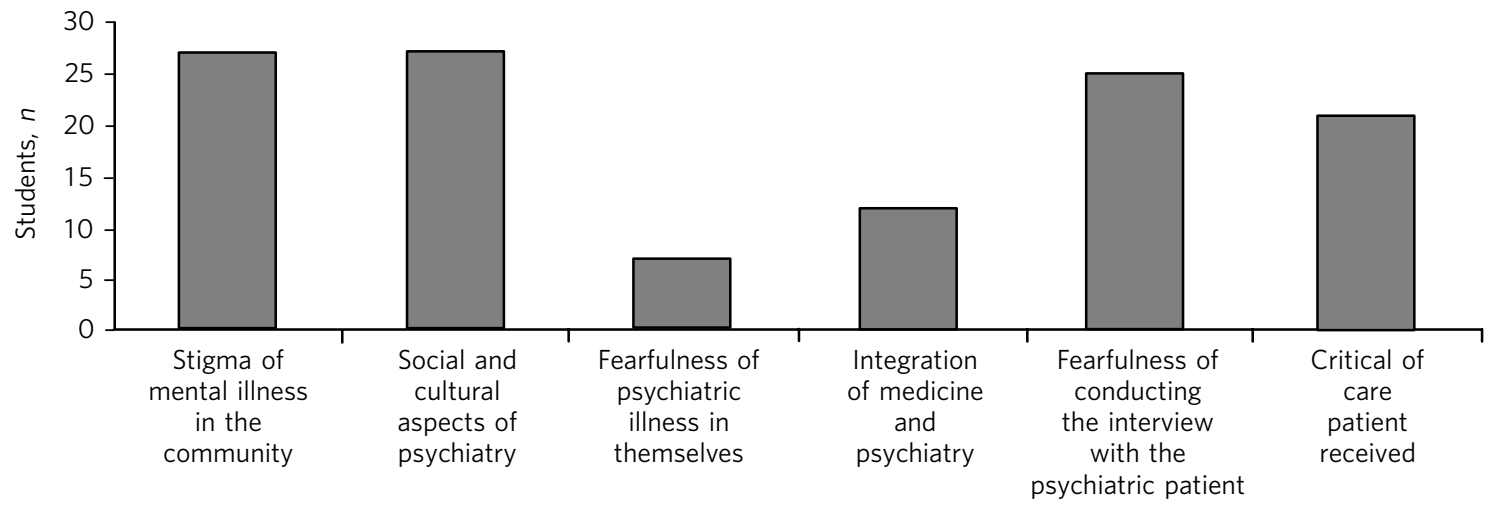

Fig. 1 Representation of themes in reflective essays.

\begin{tabular}{|c|c|c|}
\hline Theme & Theme description & $\begin{array}{l}\text { Percentage of assignments } \\
\text { where theme occurred }\end{array}$ \\
\hline Stigma of mental illness in the community & Society's stereotypical views of psychiatric illness & 27 \\
\hline Social and cultural aspects of psychiatry & $\begin{array}{l}\text { Often discussed significant influences to mental } \\
\text { illness }\end{array}$ & 27 \\
\hline Fearfulness of psychiatric illness in themselves & $\begin{array}{l}\text { Assignments referred to a vulnerability to mental } \\
\text { illness in themselves related to their experience }\end{array}$ & 7 \\
\hline Integration of medicine and psychiatry & $\begin{array}{l}\text { A reference to the interrelation of mental illness } \\
\text { and other health problems }\end{array}$ & 12 \\
\hline $\begin{array}{l}\text { Fearfulness of conducting the interview with the } \\
\text { psychiatric patient }\end{array}$ & $\begin{array}{l}\text { Apprehension of the event discussed in the } \\
\text { reflection }\end{array}$ & 25 \\
\hline Critical of care received by the patient & $\begin{array}{l}\text { The author of the assignment was disparaging } \\
\text { about the care received by the patient }\end{array}$ & 21 \\
\hline
\end{tabular}


Several students expressed frustration about stigma and how it inhibits effective care:

'This is really frustrating as it seems now [the patient] no longer wants the help because of the stigma around mental illness regardless of how much it could improve her life'.

This student showed great appreciation of the major challenges faced by the person affected by mental illness:

'I realised that people with mental illness have to bear not only the burden of their illnesses but also the burden of the social stigma attached'.

\section{Social and cultural aspects of psychiatry}

In $27 \%$ of the assignments we identified the theme of social and cultural aspects of psychiatry. Students expressed this theme in a number of different areas in patient care, some of which are illustrated by the comments below.

Some students were surprised at how important social aspects were in the management of patients with mental health problems:

'This case has highlighted the importance of having good social support'.

This student was alluding to the paternalism that is inherent in much psychiatric care, but very different to the framework of other specialties:

'When such patients begin to slot out of society, then we deem it our place to shape their beliefs and values in such a way as to slot them back in'.

This statement reflects an understanding that was repeated several times within the assignments in this theme:

'Social isolation can be a big factor contributing to [the patient's] condition'.

\section{Fear of psychiatric illness in students themselves}

Seven per cent of the assignments contained the theme of students fearing they may develop a mental illness themselves. Although this was raised less often than the previous two themes, the meaning in reflection was powerful.

Some statements extracted from the text include:

'I had to confront my human frailty'.

'I remember feeling very sorry for [the patient] but at the same time relieved that it wasn't me sitting in the other chair. Then, guilty feelings at having those thoughts and finally feeling scared that this could still happen to me one day'.

This was a revealing piece of reflection demonstrating growing awareness of the frequency of mental illness in the community, if not necessarily a positive attitude towards it.

'Whenever I see or hear about depression it does make me think and reflect on personal experiences, I must also admit to feeling depression at times'.

This statement indicates a good identification with the patient and also of the history of similar feelings in the student.

\section{Integration of medicine and psychiatry}

This theme was coded for in $12 \%$ of the assignments. Quotations from the text include:
'A realisation that psychiatric patients are ill in the same way that physically ill patients are'.

A number of the students discussed the impact of alcohol on the patients they saw:

'Social effects of alcohol but also the physical complications which can be debilitating'.

There were some really insightful reflections in this area, demonstrating a good level of learning during the attachment:

'This case has further ingrained in my mind to always think about medical/organic causes in psychiatric disorders'.

\section{Fear of conducting the interview with the psychiatric patient}

A fourth of assignments indicated that the students were in some way fearful of conducting the interview with a psychiatric patient. Some students expressed very strong opinions. The assignments in which it was brought up often demonstrated very good reflective practice. Statements from the text included:

'Knowing that she was a schizophrenic patient made me worry about my safety'.

Students were most concerned about seeing patients with schizophrenia and those with addiction problems.

'First ever experience of interviewing someone with mental illness I found it quite difficult to control the interview'.

Students often felt that controlling the interview was very important and would imply that there would be little value in interviewing someone if they could not manage this.

'Clerking [the patient] was a challenging experience and one which I will not forget in a hurry'.

The student intimates that this was a significant event in their studentship and a valuable learning opportunity.

\section{Critical of care the patient received}

Twenty-one per cent of the study assignments were critical of the care given to the patient. Most students ventured pertinent suggestions as to why this was the case, some of which are given below.

'More time should have been spent with the patient explaining how drugs work'.

Students often commented on the lack of time available for the team to see their patient.

'His story also highlighted to me that giving a patient a diagnosis and not explaining it to them, especially one such as borderline personality disorder which carried with it negative connotation, would not benefit a patient's life in any way'.

'Diagnosis was probably delayed due to ineffective communication'.

Poor communication was mentioned in many students reflections.

\section{Student feedback}

On one attachment (of 40 students) the students were also asked to provide feedback on writing the case and whether they had found it to be useful. The results are shown in 
Table 2 Views on writing the case summary and reflective piece

\begin{tabular}{lccccc} 
& $\begin{array}{c}\text { Strongly agree } \\
n(\%)\end{array}$ & $\begin{array}{c}\text { Agree } \\
n(\%)\end{array}$ & $\begin{array}{c}\text { Neither agree } \\
\text { nor disagree } \\
n(\%)\end{array}$ & $\begin{array}{c}\text { Disagree } \\
n(\%)\end{array}$ & $\begin{array}{c}\text { Strongly disagree } \\
n(\%)\end{array}$ \\
\hline $\begin{array}{l}\text { I found the experience of writing the } \\
\text { case summary beneficial }\end{array}$ & $10(27)$ & $19(51.4)$ & $4(10.8)$ & $4(10.8)$ & $0(0.0)$ \\
$\begin{array}{l}\text { I found the experience of writing the } \\
\text { reflection on the case beneficial }\end{array}$ & $6(16.2)$ & $15(40.5)$ & $7(18.9)$ & $8(21.6)$ & $1(2.7)$ \\
\hline
\end{tabular}

Table 2. Out of a total 40 students, 37 gave feedback. Below are selected comments.

'Reflection was harder than I expected. Case was easy to write due to template. Reflection was hard, made me think'

'Thorough case [history] was a good [experience]. Reflective part was of little use - waffling on until you satisfy the [word] count - I'm glad I was not marking them'.

'Good to gain experience in writing a formal case. Reflection is useful in professional practice'.

\section{Discussion}

Reflective practice is an increasingly important part of undergraduate and postgraduate training. This study aimed to analyse the content of students' first piece of reflection in psychiatry and to assess their views on the process.

A hundred assignments were consecutively selected. This was approximately a third of the assignments for the year and as such was a reasonable proportion. The clinical attachments repeat on a rolling cycle 6 times a year, which makes up three consecutive attachments. There is no reason to think that these assignments would be in any way unrepresentative of the whole year's cohort.

The study aims lent themselves to qualitative analysis. We had both marked many assignments before so although we started the process with no prima facie hypotheses, we will inevitably have formed some views about the nature and quality of the students' reflection. Some of the aspects of the case discussed by students did not fit neatly into themes and for some areas of discussion thought had to be given as to which theme it fitted best, especially as regards the stigma and sociocultural themes which are conceptually similar.

Students were struck by the stigma facing patients who have mental health problems. About a third of students mentioned it, focusing on either the negative attitudes about mental illness they personally had in the past or the obvious stigma the patients had experienced, and comparing this to other specialties where there is much less stigma. Some of the most mature reflection was expressed in the themes of sociocultural issues and awareness of possible illness in themselves. The sociocultural theme was broad, with students discussing aspects such as the impact of the patient's illness on their family, the importance of family support, and how people with a mental illness 'fit' in society. The more empathic students wrote about fear of becoming mentally ill themselves. A small minority did this because of past personal experience, but for most they were just struck by the fact that mental illness can happen to anyone. Some pointed out that on other rotations they were used to seeing elderly patients and found it disconcerting to see young patients, possibly of a similar background to their own.

Students discussing the integration of mental and physical illness either emphasised the importance of excluding and treating physical problems, or made interesting comparisons between general medicine and psychiatry. We were surprised to read how apprehensive the students admitted to being before seeing a patient with mental health problems. A small number were anxious about their safety, but most were worried about whether they would be able to take a proper history and control the interview. Reflection on practice is felt to enhance skill development and we felt that those expressing anxiety were insightful about the difficulties that can arise when taking a psychiatric history. ${ }^{8}$ Beylefeld et al report students admitting, in a reflective piece of work, to anxiety prior to seeing a primary care patient in the community; ${ }^{9}$ it may be that we underestimate how anxiety-provoking seeing patients can be for students.

It was both interesting and concerning that approximately a fifth of students shared criticisms of the care received by the patient. Hicks et $a l^{10}$ looked at students' experience of care that they considered to be substandard and the ethical problems faced by students in this situation. Most of the examples in this study related to poor communication and perceived lack of time clinicians could devote to patients. Students are unlikely to criticise clinicians teaching them directly, but this is a potentially useful source of feedback, especially as the students come to the specialty with a 'fresh eye'. This would be an interesting area of future research. It would also be informative to be able to discuss the content of reflection with students; Sandars argues that guided reflection is important so that issues can be discussed and views challenged, ${ }^{11}$ and this would be a useful exercise.

In keeping with the model of reflective practice, it was important for us to use the evidence obtained to reflect on how we run the psychiatry attachment and look at ways to improve it. Reflective writing can stimulate curriculum development by providing feedback. ${ }^{9}$ One of the key points raised by the students was fear of their first meeting with a psychiatric patient. As a result, we have changed our induction, spending more time discussing this with students and encouraging them to interview the first few patients they saw in pairs.

The General Medical Council considers doctor and trainee 'attitudes' as core factors important to becoming a doctor. There is enormous stigma associated with mental illness ${ }^{12,13}$ and this extends to psychiatry as a career, which is viewed in a negative way by many students and members of the medical profession. ${ }^{14,15}$ It is too ambitious to aim to 
change attitudes markedly towards the specialty of psychiatry simply by asking students to produce a piece of reflective work, but it may at least start them thinking more deeply about the specialty. The teaching of psychiatry has been found to be formative of attitudes towards it. ${ }^{16-18}$ Wilkinson et al found that exposure to the clinical specialty as students did improve pre-existing negative attitudes. ${ }^{19}$ This is an area that may warrant further research.

Many students found it difficult to write a piece of reflective work. Some research shows those felt to be less good at reflection are more negative about it in general, ${ }^{20}$ although this was not found by Beylefeld et al. ${ }^{9}$ Obviously, some students are going to be more naturally open to the process than others. There is a danger that those less open to reflection may acquire a more negative view of psychiatry if asked to do it as part of the assessment. However, reflective assignments will form part of a portfolio for the continuous assessment of doctors in their career and it is important for medical students to become accustomed to the practice.

We asked for the reflective piece to be written as part of the students' formative assessment at the end of the attachment. Formative assessment provides with valuable feedback not only for the learner but also for the teachers and the school. ${ }^{21}$ We certainly found this to be the case in this instance.

The attitudes of medical students will shape the direction of their future careers. Positive attitudes to psychiatry may also help students manage patients of other specialties, many of whom will experience psychological difficulties. ${ }^{22}$ It is important that as teachers and educators we understand students' ideas so we can modify their attachment to facilitate their enjoyment of the subject.

\section{About the authors}

Dr Aileen O'Brien, senior lecturer in psychiatry, Division of Population Health Sciences and Education, St George's, University of London, Cranmer Terrace, Tooting; Dr Jeremy Mudunkotuwe, consultant psychiatrist, Epsom, Ewell and Banstead Primary Care Mental Health Team, Farmside, West Park Hospital, Horton Lane, Epsom, Surrey.

\section{References}

1 Gibbs G. Learning by Doing: A Guide to Teaching and Learning Methods. FEU, 1988.

2 Svenberg K, Wahlqvist M, Mattsson B. 'A memorable consultation': writing reflective accounts articulates students' learning in general practice. Scand J Prim Health Care 2007; 25: 75-9.

3 Eagles JM, Wilson S, Murdoch JM, Brown T. What impact do undergraduate experiences have upon recruitment into psychiatry? Psychiatr Bull 2007; 31: 70-2.
4 Brown N, Vassilas CA, Oakley C. Recruiting psychiatrists - a Sisyphean task? Psychiatrist 2009; 33: 390-2.

5 Crisp A, Gelder M, Goddard E, Meltzer H. Stigmatization of people with mental illnesses: a follow-up study within the Changing Minds campaign of the Royal College of Psychiatrists. World Psychiatry 2005; 4: 106-13.

6 Lambert TW, Turner G, Fazel S, Goldacre MJ. Reasons why some UK medical graduates who initially choose psychiatry do not pursue it as a long-term career. Psychol Med 2006; 36: 679-84.

7 Westmoreland GR, Counsell SR, Sennour Y, Schubert CC, Frank KI, Wu J, et al. Improving medical student attitudes toward older patients through a 'council of elders' and reflective writing experience. J Am Geriatr Soc 2009; 57: 315-20

8 Pee B, Woodman T, Fry H, Davenport ES. Appraising and assessing reflection in students' writing on a structured worksheet. Med Educ 2002; 36: 575-85.

9 Beylefeld AA, Nena KD, Prinsloo EA. Influence of community experiences on first-year medical students' reflective writing. Med Teach 2005; 27: 150-4.

10 Hicks LK, Lin Y, Robertson DW, Robinson DL, Woodrow SI. Understanding the clinical dilemmas that shape medical students' ethical development: questionnaire survey and focus group study. BMJ 2001; 322: 709-10.

11 Sandars J. The use of reflection in medical education: AMEE Guide No. 44. Med Teach 2009; 31: 685-95.

12 Crisp AH, Gelder MG, Rix S, Meltzer HI, Rowlands OJ. Stigmatisation of people with mental illnesses. Br J Psychiatry 2000; 177: 4-7.

13 Mehta N, Kassam A, Leese M, Butler G, Thornicroft G. Public attitudes towards people with mental illness in England and Scotland, 19942003. Br J Psychiatry 2009; 194: 278-84.

14 McParland M, Noble LM, Livingston G, McManus C. The effect of a psychiatric attachment on students' attitudes to and intention to pursue psychiatry as a career. Med Educ 2003; 37: 447-54

15 Sivakumar K, Wilkinson G, Toone BK, Greer S. Attitudes to psychiatry in doctors at the end of their first post-graduate year: two-year follow-up of a cohort of medical students. Psychol Med 1986; 16: 457-60.

16 Burra P, Kalin R, Leichner P, Waldron JJ, Handforth JR, Jarrett FJ, et al. The ATP 30 - a scale for measuring medical students' attitudes to psychiatry. Med Educ 1982; 16: 31-8.

17 Creed F, Goldberg D. Students' attitudes towards psychiatry. Med Educ 1987; 21: 227-34.

18 Singh SP, Baxter $H$, Standen $\mathrm{P}$, Duggan $\mathrm{C}$. Changing the attitudes of 'tomorrow's doctors' towards mental illness and psychiatry: a comparison of two teaching methods. Med Educ 1998; 32: 115-20.

19 Wilkinson DG, Toone BK, Greer S. Medical students' attitudes to psychiatry at the end of the clinical curriculum. Psychol Med 1983; 13: 655-8.

20 Rees C, Sheard C. Undergraduate medical students' views about a reflective portfolio assessment of their communication skills learning. Med Educ 2004; 38: 125-8.

21 Nicol D, Macfarlamne-Dick D. Formative assessment and self-regulated learning: a model and seven principles of good feedback practice. Stud Higher Educ 2006; 31: 199-218.

22 Nielsen 3rd AC, Eaton Jr JS. Medical students' attitudes about psychiatry: implications for psychiatric recruitment. Arch Gen Psychiatry 1981; 38: 1144-54 